\title{
El Área de Seguridad Conjunta en el cine nacionalista de Corea del Sur
}

\author{
The Joint Security Area in the nacionalist cinema of South Korea
}

José Óscar Ávila Juarez ${ }^{1}$

\section{Resumen}

La guerra de Corea entre 1950 y 1953 dio como resultado la creación de una frontera que separó en dos partes la península coreana: Norte y Sur. El lado norteño respaldado por la ideología comunista, mientras que el sureño por la capitalista. A partir de la conclusión de la guerra civil se activó en el área fronteriza un estado de tensión, mismo que dominó la relación por varias décadas. Precisamente, la película Área de seguridad conjunta de Park Chan-Wook, presenta dicho enfrentamiento por medio de la amistad de cuatro soldados, dos del Sur y dos del Norte. Encontrados de manera circunstancial, construyen una amistad que se ve truncada por los odios ideológicos que enmarcan sus respectivos países. La intermediación de la Organización de las Naciones Unidas ${ }^{2}$ a través de una funcionaria con raíces coreanas, dibuja más el conflicto ideológico, descubre la verdad del suceso que estuvo a punto de provocar una guerra entre las Coreas, pero al mismo tiempo, devela la rivalidad ideológica que persiste en la península. Al tener este desenlace la trama cinematográfica, el director Park enfatiza que persisten trabas para la unificación. Sin embargo, con las escenas finales, donde muestra a los amigos sonriendo, el cineasta pondera la esperanza de un cambio en la relación de las dos Coreas.

Palabras clave: Corea, guerra, frontera, tensión, esperanza

\section{Abstract}

The Korean War (1950-1953) resulted in the creation of a border that separated the Korean peninsula into two parts: North and South. The northern side backed by communist ideology, while the southern side by the capitalist. After the conclusion of the civil war, a state of tension emerged in the border area, which dominated the relationship for several decades. Precisely, the Joint Security Area film (Park Chan-

Recibido: 06 de noviembre de 2019 Aceptado: 1 de diciembre de 2019 Publicado: 20 de diciembre de 2019

${ }^{1}$ Doctor en Ciencias Sociales, Profesor Investigador de la Universidad Autónoma de Querétaro (UAQ), Santiago de Querétaro, estado de Querétaro, México. Correo electrónico: amorom_99yahoo.com.

${ }^{2}$ En adelante $\mathrm{ONU}$. 
Wook, 2000) presents this confrontation through the friendship of four soldiers, two from the South and two from the North. Circumstantially, they build a friendship that is truncated by the ideological hatreds that frame their respective countries. The intermediation of the United Nations Organization depicted by an official with Korean roots, draws more ideological conflict, because she discovers the truth of the event that was about to cause a war between the Koreas, but at the same time, reveals the ideological rivalry that persists in the peninsula. Director Park emphasizes that obstacles to unification persist. However, with the final scenes, where he shows the friends smiling, the filmmaker ponders the hope of a change in the relationship of the two Koreas.

Keywords: Korea, war, border, tensión, hope

\section{Guerra y separación}

La derrota de Japón en la Segunda Guerra Mundial resultó para Corea un alivio, que pronto se volvió una pesadilla, luego que los vencedores del enemigo, Estados Unidos y la Unión Soviética, decidieran convertir el territorio coreano en un campo de batalla en el marco de la Guerra Fría. Al derrotar a los japoneses, estas dos naciones concretaron separar Corea entre la parte soviética y la estadounidense (Norte y Sur, respectivamente), mediante el paralelo 38. Los dimes y diretes por la hegemonía planetaria supusieron otro orden enmarcado por el "juego" ideológico de ambas potencias que dio como resultado su disputa en terrenos neutrales. La primera de ellas se dio en Alemania en 1949, separada arbitrariamente por estas mismas naciones apelando a su "legítima" ocupación como parte de la guerra. Otra cereza del pastel fue el conflicto de Corea iniciado en 1950, donde los estadounidenses amparados por la ONU (y respaldados por una decena de países), decidieron recuperar el territorio arrebatado por los comunistas coreanos y acabar de tajo con la amenaza de este bloque.

El 25 de junio de 1950, los líderes del Norte acordaron invadir el Sur y, con esto, provocaron una escalada de Estados Unidos en la península coreana. La tensión en el área se incrementó aún más en 1951 cuando el general Douglas MacArthur (1880-1964), al mando de las tropas estadounidenses, decidió rebasar el paralelo 38 y controlar definitivamente el Norte. Esta maniobra resultó contraproducente al provocar la entrada de China al conflicto para apoyar a los del Norte. La guerra de Corea concluyó el 27 de julio de 1953, luego de fieros combates entre las dos partes. El resultado fue regresar de nuevo a la línea fronteriza del paralelo 38, enalteciendo una zona desmilitarizada de 4 kilómetros defendida de un lado por los de Norte, y por 
el otro lado, por los del Sur, bajo la custodia de Estados Unidos y la ONU. (Pike, 2010, p. 267). ${ }^{3}$ De manera contrastante, la frontera también se convirtió en una belicosa Área de Seguridad Conjunta entre las dos Coreas.

A pesar del esfuerzo por garantizar una relativa paz en la península de Corea, esta se vio envuelta en la dinámica de la Guerra Fría, enfrentamiento visiblemente político e ideológico liderado por los Estados Unidos y la Unión Soviética. En medio de esta disputa por la supremacía mundial, las dos Coreas levantaron a su vez su propia cortina ideológica entre ambas, respaldada tajantemente por las dos superpotencias. Por un lado, Syngman Rhee como líder del Sur (1948-1960) y, por el otro, Kim Il-Sung como líder del Norte (1948-1994), hicieron todo de su parte para perpetuar la tensión entre ambos bandos. Para el caso del Sur, Park Chung-Hee, ascendido en 1963, condujo la misma ruta de Rhee mediante una dictadura que duró hasta 1981. Lapso en el cual hubo un crecimiento económico sin precedentes y un boom industrializador que derivó en la exportación de bienes pesados y químicos. A este periodo de prosperidad se le conoció como "El milagro del río Han", lapso en que se proyectó Corea del Sur a las grandes ligas de la economía mundial (Hyong, 2008, p. 138). Mientras que su oponente, Corea del Norte, mantuvo una política de aislamiento bajo el dominio de un líder único.

$\mathrm{Al}$ ascenso del Sur le siguieron varios tropiezos en la economía y en la política, pero en el segundo lustro de los ochenta, el país pareció convencer nuevamente al mundo de su dinamismo, y, en 1988, organizó Los Juegos Olímpicos; en 1995, ingresó a la Organización Mundial del Comercio; y en 1996, a la Organización para la Cooperación y Desarrollo Económico. A pesar de la crisis acaecida entre 1997 y 1998, en los siguientes años dio un salto cualitativo de recuperación, y con esto, Corea del Sur se reafirmó como una nación exportadora por excelencia, destacando en ramos como el automotriz y el electrónico. (Hyong, 2008, pp. 139 y 140).

Por su parte, el Norte, aislado convenientemente y amparado en la filosofía Juche, ${ }^{4}$ siguió su política de enfrentamiento con Estados Unidos, Japón y Corea del Sur. (Escalona Agüero, 2009, p. 198) Este país comunista, alegando tener armas nucleares, mantuvo en zozobra a la región. Incluso, entre sus propios habitantes, quienes en el aislamiento sufrieron de carencias elementales para la existencia humana.

El 15 de junio de 2000, bajo el liderazgo del presidente surcoreano Kim Daejung (1998-2003) se impulsó una Declaración conjunta Sur-Norte de

\footnotetext{
${ }^{3}$ Al final, la guerra de Corea registró un millón de muertos por el lado del Sur, otro millón de parte del Norte y casi un millón de desaparecidos entre los dos bandos. También participaron Gran Bretaña, Canadá, Australia, Nueva Zelanda, Turquía, Bélgica, Colombia, Etiopía, Francia, Grecia, Holanda, Filipinas y Tailandia. Los Estados Unidos perdieron 33629 combatientes, y entre todos los demás países murieron 3063 personas.

${ }^{4}$ Esta filosofía pondera valores comunistas coreanos que deposita la revolución en las masas, aunque, también atribuye caracteres de liderazgo permanentes a sus líderes como Kim Il-Sung y Kim Jong-Il (1994-2011).
} 
reconciliación con el lema "Sunshine Policy". ${ }^{5}$ Por esta misma iniciativa se dieron los primeros pasos para trabajar en conjunto temas de desarrollo industrial, transporte y turismo. (Hyong, 2008, p. 141) Sin embargo, estos esfuerzos se vieron reducidos más adelante por las visiones políticas e ideológicas intolerantes de los líderes de ambas naciones, quienes a pesar de los muchos cambios en el mundo (como la caída del muro de Berlín en 1991 y el ocaso del bloque comunista en Europa a partir de 1993), mantuvieron en incertidumbre a sus ciudadanos bajo la amenaza de una nueva guerra en la península coreana. Este es el meollo de la película Área de Seguridad Conjunta de Park Chan-Wook (2000), una interpretación de la tensión bélica que bordea los hilos de una amistad maniatada por el conflicto nacional.

\section{Representación cinematográfica de la Área de Seguridad Conjunta}

La relación Cine-Historia es un fenómeno relativamente nuevo, aparece en el decenio de los sesenta, y lo hace a través de un debate propiciado por Siegfried Kracauer, quien inserta las teorías del cine bajo la mirada histórica. ( Kracauer, 2015) Más adelante, Marc Ferro alude al cine para problematizar la historia contemporánea.(Ferro, 2016) Igual visión tiene Robert A. Rosenstone, quien a su vez pregona que para que el cine alcance validez precisa de guiones históricos.(Rosenstone, 2014) Por su parte, Pierre Sorlin va más adelante en el análisis y propone que el cine con sus características propias representa a la sociedad en cuando a que es producto de la misma acción social.(Sorlin, 1985) Mientras que Peter Burke señala que la propuesta cinematográfica tiene que ser observada y criticada por los historiadores como parte de su proceso de actualización y mejora sistemática en la comprensión del pasado (Burke, 2001)

Estos autores han conjuntado un repertorio teórico-metodológico importante para "aligerar" el diálogo Cine-Historia tomando en cuenta que retratan los mismos aspectos sociales, aunque, con diferente acercamiento. Y lo digo porque hay veredas comunes entre la Historia y el Cine como la observación, explicación, análisis e interpretación de las prácticas sociales del hombre, pero también hay otras que las separan como los objetivos, problemas y síntesis que aplica el estudio historiográfico.

Vemos entonces que el filme Área de Seguridad Conjunta de Park Chan-Wook estrenado en el 2000, es una representación de la tensión fronteriza entre las dos Coreas, que instaurada en 1946, sigue siendo un tema polémico y delicado para las sociedades de ambas naciones. Al concluir la guerra en 1953, la ONU bajo el liderazgo

\footnotetext{
${ }^{5}$ Compromiso incondicional para una posible reunificación entre las dos Coreas.
} 
de Estados Unidos y en pleno conflicto ideológico de este último país con la Unión Soviética, decidió establecer un espacio administrado por este organismo supranacional para garantizar neutralidad y así evitar una confrontación con pronósticos reservados. Sin embargo, desde su creación, este espacio ha estado envuelto en polémicas por lo grave que representa mediar entre dos países que se acusan mutuamente de agredirse. A pesar de los intentos por disminuir la tensión y buscar alguna reconciliación, los esfuerzos han sido en vano y la zozobra en el lugar sigue latente.

Por otro lado, el director Park nace el 23 de agosto de 1963 en Seúl, Corea del Sur. Estudia filosofía en la Universidad de Sosang, donde organiza un cine club y se adentra en los menesteres cinematográficos. ${ }^{6}$ Su vida universitaria estuvo marcada por el debate democrático y el ascenso económico que catapultó a Corea del Sur como una de las naciones más prometedoras del sistema capitalista.

Teniendo como telón de fondo esta vertiginosa transformación, Park filma sus primeras películas: la primera, denominada Moon is the sun's dream (1992), que es un conflicto de mafiosos que tiene como trama la fuga de la novia del jefe con uno de los subalternos; la segunda, Saminjo (1997), trata la vida criminal orquestada por un saxofonista, un tipo violento y una madre soltera; la tercera es un corto denominado Simpan (1999), que reúne a dos familias, quienes reclaman el cuerpo de una mujer asesinada; y la cuarta, Anakiseuteu Anarchists (2000), que alude a un grupo de coreanos anarquistas en el decenio de los veinte. ${ }^{7}$

En este primigenio repertorio fílmico presentado por Park Chan-Wook se muestran las vidas de los individuos al límite. Sus películas son un juego de ideas y sentimientos que se mezclan con situaciones que aluden a los protagonistas. Por ende, el cineasta no esconde su firme intención de representar a los individuos tomando decisiones en situaciones complejas. Este cine de autor no tuvo mayor éxito comercial $y$, por ende, sus creaciones iniciales constituyeron su primera decepción en el ámbito cinematográfico. Sin embargo, su tristeza se volvió alegría cuando representó en el cine un tema de vital importancia para su país: el conflicto entre las dos Coreas mediante la cinta Área de Seguridad Conjunta.

Cuando se proyectaría el filme, las dos Coreas vivían un momento de acercamiento, marcado por la política del presidente surcoreano Kim Daejung de hacer un llamado a la reconciliación. Mismo que aceptaría en una primera instancia su homólogo de Corea del Norte, Kim Jong-Il. Pero, tal como lo proyecta Park ChanWook en la cinta, el discurso distaba mucho de la realidad y los enfrentamientos seguirían a flor de piel más adelante. A pesar de esto, como el tema de la película estaba

\footnotetext{
${ }_{7}^{6} \mathrm{http}: / /$ decine21.com/Biografias/Park-Chan-wook-54816. 30 de agosto de 2016.

${ }^{7}$ Idem. y http://www.imdb.com/name/nm0661791/?ref_=fn_al_nm_1. 30 de agosto de 2016.
} 
en boca de todos, tendría una excelente recepción entre los espectadores convirtiéndose en la película más taquillera de la historia de Corea del Sur, y esto, catapultaría la carrera cinematográfica de Park. $^{8}$

\section{Problemática de la película Área de Seguridad Conjunta}

A finales del segundo milenio, las dos Coreas se prepararon militarmente para atacarse debido a un incidente en el Área de Seguridad Conjunta en Panmunjom, misma que involucró la muerte de dos oficiales de Corea del Norte en territorio de seguridad de este último país. Este acontecimiento alarmó a los dirigentes de la ONU, quienes constituyeron una Comisión Supervisora de Estados Neutrales para conocer lo sucedido y deslindar responsabilidades. Presidida por Suiza y Suecia, el protagonismo de la misma la tiene una oficial, hija de un coreano y una suiza, quien habla perfectamente coreano.

Ella inicia su procedimiento para indagar sobre el tiroteo donde murieron dos soldados norcoreanos y resultó herido uno del Sur. En primera, la funcionaria capta cierta tensión ocasionada por una cultura de fricciones entres las dos Coreas, por lo que, su primer encuentro con un oficial surcoreano fue tenso. De inmediato percibe versiones encontradas de los testigos y alberga ciertas dudas acerca de la verdad del acontecimiento. Mientras que alrededor del Área de Seguridad Conjunta, ambas naciones pregonan acercamiento.

$\mathrm{Su}$ primera entrevista la hace al soldado surcoreano herido, quien algo alterado, se muestra a la defensiva y evita hablar del enfrentamiento. Parece un hombre dedicado a la milicia, buen tirador y con una vida normal. Enseguida, el director de la película Park Chan-Wook hace alarde del recurso cinematográfico y muestra el tiroteo y hace evidente la división de las naciones cuando la comisionada arriba al sitio del conflicto. Luego, vemos a la funcionaria de la ONU cruzar la frontera al Norte y entrevistar al soldado sobreviviente, quien se niega a comentar el suceso. En esto, recuerda la escena poniendo a su enemigo del Sur como el asesino de sus compañeros. La versión del soldado del Norte va acompañada por la visita a la morgue donde la comisionada analiza los cuerpos de los dos soldados muertos y descubre la dirección de los impactos de bala en medio de un montaje del gobierno norteño de pesar familiar por los fallecidos. Más adelante, entrevista a los amigos del soldado del Sur y le proporcionan datos sobre su personalidad y del incidente de la mina.

\footnotetext{
${ }^{8}$ http://decine21.com/Biografias/Park-Chan-wook-54816. 3 de septiembre de 2016.
} 
$\mathrm{Al}$ ir entrando en detalles y sacando conclusiones del trabajo de campo y las entrevistas, la oficial de la ONU descubre que los reportes de ambos lados fueron intencionalmente falsificados, pues ninguno de ellos reportó una bala más encontrada en la acción violenta. Este incidente ocasiona un nuevo cuestionamiento a los soldados del Sur. Primero, entrevista al compañero del herido, quien supuestamente se encontraba en la base, y al ser cuestionado, caería en contradicciones sobre su participación en el conflicto. Luego consulta al herido sobre su destreza en las armas y confirma su habilidad como tirador. También, entrevista a la novia, quien resulta hermana de su compañero de base, el otro entrevistado.

Más adelante, la comisionada volvería a consultar al soldado herido del Sur confrontándolo sobre las balas, advirtiéndole que en la escena había sido encontrada una bala de más, y que por lógica no pertenecía a su arma, sino a la de su compañero de la base, y le pregunta sobre el paradero de la bala. Debido al acorralamiento de la entrevistadora, el soldado accede a contarle lo acontecido en la mina. Mientras tanto, otro oficial de la ONU entrevista a su compañero de vigilancia, haciéndole el mismo cuestionamiento sobre los disparos en el enfrentamiento, advirtiéndole que en el Norte habían encontrado sangre de uno de los soldados muertos en su pistola. Ante esto, éste último entra en pánico y trata de suicidarse aventándose de un segundo piso, resultando herido, quedando en estado de coma.

A partir de esto, nuevamente sale el recurso del cine y el director Park recurre a la historia del acontecimiento narrando el inicio de la trama. Meses antes, en medio de la tensión en el Área de Seguridad Conjunta, se llevaba a cabo una visita de paseantes extranjeros, y una turista perdía una gorra arrebatada por el viento, misma que caería en el lado norteño, a lo que un soldado de este lado reaccionaría regresando la prenda con una sonrisa, y dejándose tomar fotografías por la visitante. Acto seguido, se presentaría otra escena ocurrida antes de esta acción amistosa, donde un grupo de soldados del Sur saldría a su recorrido de vigilancia en la línea divisoria, y en un descuido, uno de ellos, se rezagaría por realizar sus necesidades fisiológicas, y cuando enfilaba el paso para seguir a sus compañeros, pisaría una mina terrestre. En este momento complicado, el soldado descubre que no había nadie de su lado para ayudarlo, por lo que esperaría reposando en la mina. Más tarde, escucharía los pasos de unos soldados del Norte, quienes por los ladridos de un perro se darían cuenta que el soldado del Sur estaba parado sobre una mina. Al ver a los enemigos, el sureño se asustaría, pero ante su angustia en la mina, les pediría ayuda llorando, un oficial norteño decidiría apoyarlo desactivando la mina. Al partir, el soldado solidario se despediría del surcoreano con una sonrisa. Luego de este momento se entablaría una relación entre los tres soldados involucrados. 
Lo que sigue después es la verdadera problemática de la película, cuando en medio de las tensiones se presentan signos de camaradería entre los soldados de ambos bandos. En una acción, una patrulla del Sur se encuentra frente a frente con sus enemigos, y los oficiales al mando proceden a intercambiarse saludos y un cigarrillo. En esto, el soldado de la mina reconoce al oficial del Norte, pues resulta ser el mismo que le salvó de la muerte unos días antes, por lo que interpreta este acercamiento como posibilidad para agradecer a su salvador. Más adelante se vuelven a encontrar vigilando la línea fronteriza custodiada por la ONU y se cruzan sonrisas. Esto es tomado por el surcoreano como señal de aceptación y decide intercambiar mensajes con su par norteño.

Una noche en que estaba con su compañero de la base sureña, decide brincar al Norte para buscar al soldado que le había salvado la vida. Después de la sorpresa, los norteños le dan la bienvenida y, uno de ellos, el subalterno, le dice al sureño de manera simbólica que este encuentro es un paso para la reunificación de las dos Coreas. Después de este encuentro, la amistad se fortalece con el cruce frecuente del soldado del Sur al lado norteño. A partir de esto, el director Park Chan-Wook decide poner horas y fechas para señalar los encuentros enalteciendo los valores pacíficos plasmados por las muestras de amistad que día a día crecía entre los soldados.

Mientras que el soldado de la mina se escapa al Norte, donde convive con los norcoreanos, su compañero de la base sureña le señala su tristeza por su próximo retiro de la milicia, ante esto, duda en decirle de la amistad con los soldados del Norte; pero una noche en que su compañero dormía en su turno de vigilancia, aprovecha para ir a ver a sus amigos norteños, y cuando estaba en camino, su compañero despierta y se percata de su ausencia, por lo que este va al puente y lo descubre a punto de cruzarse para el lado del Norte. El soldado de la mina le cuenta su secreto a su compañero y lo invita a pasarse al lado norteño. Pronto, el compañero del protagonista también participará en la relación de convivencia con sus pares del otro lado del puente. Una frase pronunciada por el soldado de la mina logra convencer a su compañero de base: "medio siglo de dolor y deshonra, un salto a la reunificación". Este mensaje proviene netamente del director Park, quien utiliza el recurso cinematográfico para plasmar su preocupación por el problema fronterizo y vislumbra una necesidad de lograr acuerdos entre las dos Coreas. Por lo que, de manera intencionada, estrecha la relación de los cuatro soldados, quienes a lo largo de sus encuentros enaltecen los sentimientos, y como buenos camaradas, intercambian cosas materiales y, sobre todo, afecto. El prolongado contacto se traduce en una amistad fronteriza colgada de un hilo. Un caso sobresaliente que presenta el cineasta es la escena del choque ideológico entre el soldado de la mina y su salvador, cuando este último estaba comiendo un "choco pie", el primero al ver un futuro de 
separación, le pide al segundo que se vayan al Sur. Este comentario ocasionó un lapso de tensión entre todos, el del Norte le avienta al del Sur el "choco pie" y le manifiesta su satisfacción por vivir en su país y, además, le agrega que su sueño es que el Norte sea mejor que el Sur. Después de este desaguisado que simbolizaba una tensa amistad por ideologías y creencias nacionalistas, siguieron los afectos de ambos lados, y conforme pasaron los días se hicieron más amigos.

Cuando se produjo una emergencia por un avance del Norte en el Sur, los amigos se cuestionan una posible guerra y la lealtad a sus respectivos países. Aquí, el director Park Chan-Wook muestra la sensibilidad de los protagonistas. Cuando se reúnen tres días después del suceso, Park humaniza a los soldados confrontados por la guerra, y para lograrlo, inserta un silencio intencionado en una de las escenas, una reflexión necesaria; y, más adelante, le mete más sentimiento a la escena al introducir música triste para todos los presentes, quienes como muestra de amistad firman cartas de pacificación y se toman fotografías. Como colofón, uno de los soldados del Sur le da un presente a otro del Norte por su cumpleaños, por lo que, los cuatro se ponen nostálgicos.

Aquí, el cineasta vuelve a jugar con el recurso cinematográfico al regresar al intento de suicidio del soldado del Sur. Al percatarse de este hecho, su compañero de la mina se vuelve loco de ira y ataca a la oficial de la ONU dando muestra de su frustración por la acción de su amigo. Después de este episodio, la comisionada pacta una reunión entre los soldados heridos en el enfrentamiento. El encuentro es actuado por ambos amigos, y simulan un odio ideológico. Cuando la funcionaria atrae el asunto del soldado suicida, nuevamente su compañero sureño se pone mal, y al ver el norteño que su amigo se iba a desplomar por la noticia y, por ende, hablar de lo que verdaderamente había sucedido esa noche, finge una pelea y alborotan a los presentes.

Como evidencia de lo complejo del asunto, el director Park Chan-Wook propone enredar más las cosas, y lo hace en la escena cuando la comisionada es requerida por su jefe de la Comisión Neutral, quien le comenta que su padre había sido un soldado del Norte, que en medio del enfrentamiento desertaría para irse a un país neutral. Para corroborar lo anterior, Park recurre a escenas reales de un campo de prisioneros del Norte en una isla del Sur. Alude que de los 170 mil prisioneros, 76 habían decidido salirse del conflicto y rechazado su posición como combatientes. Uno de ellos había sido el padre de la comisionada, quien en Argentina conocería a la madre de ella. Acción seguida, el oficial en jefe de ella, le dice, recordando el pasado de su padre, que para promover la paz había que ocultar verdades, haciendo alusión al pasado comunista de su padre. Este recurso del director de la película enfatiza su sensibilidad hacía el tema que confiere a la comisionada. Como evidencia de que el asunto no debe tener solución para la estabilidad de la zona, el jefe de la comisión le 
dice a su oficial que un alto mando de Sur la había investigado y, al conocerse la historia de su padre, había manifestado su disgusto por su participación en la comisión. Por lo que, le dice el jefe que su labor como comisionada había concluido solicitándole su regreso a Suiza. A manera de reflexión se presenta a la oficial recorriendo la línea divisoria del Área de Seguridad Conjunta, y las imágenes capturan ambos lados separados por una franja azul y una vigilancia permanente.

Luego, la comisionada entrevista nuevamente al soldado de la mina, este le dice que ya sabe del pasado de su padre. En esto, la funcionaria lo encara y le señala que su supuesta novia no es en verdad su novia y que un retrato de ella había sido encontrado en el espacio de la confrontación, en manos de un soldado del Norte, por lo que, al sacar conjeturas del asunto, la comisionada le vuelve hablar de la bala no encontrada y le dice que tenía dos informes para entregar, uno falso y uno verdadero, le pregunta al soldado sureño sobre cual quería que entregara. También, le ofrece la seguridad de su amigo norteño. Aquí, resurge el recurso cinematográfico y Park presenta el día del acontecimiento trágico. Y resulta, que cuando estaban conviviendo los dos amigos del Sur con los dos del Norte, aparece un tercer soldado norcoreano, y se arma la trifulca al notar este último la presencia de los del Sur. Primero, el soldado salvador de la mina calma la tensión y logra que los dos soldados apuntándose (uno del Sur y el otro del Norte) bajaran las armas, pero luego, la radio casetera retorna la música, y ese ruido, regresa la tensión y se disparan. Las imágenes presentadas por el cineasta denotan la tensión entre las dos Coreas, ahora trasladada a los individuos, a los soldados. El compañero de la mina dispara al tercer soldado norteño y a uno de sus amigos, luego el de la mina también le tira al mismo amigo y le apunta a su salvador. El amigo norteño caído logra darle al de la mina, y el compañero sureño de este, le vacía el arma a su amigo norteño herido. Luego este último, el compañero sureño, corre despavorido a su cuartel dejando a su compañero en el Norte. Su salvador lo convence de bajar el arma y le da un balazo de muerte al tercer soldado, y le dice su salvador que hay que simular un ataque mutuo para protegerse de las investigaciones. Incluso, le pide que le dispare en el hombro para aparentar un forcejeo. Le explica su salvador que les diga que lo raptaron y que también les diga que su compañero sureño no se encontraba en el cuartel del Norte. Luego de este episodio llegan los refuerzos de ambos lados y se arma el conflicto mayúsculo. El soldado sureño se ve tirado en medio del puente y ve volar las balas al por mayor, y en el ambiente escucha la canción de la amistad que había escuchado en la reunión con sus amigos. Mientras tanto, su salvador mira en el horizonte que se llevan a su amigo sureño para resguardarlo.

Sabiéndose lo ocurrido, el director Park pasa al desenredo de la historia. Las deducciones de la oficial de la ONU van tomando forma, cuando vuelve a entrevistar 
al soldado herido del Norte le pregunta sobre la muerte de su compañero de la base, $\mathrm{y}$ al ver que no quiere decirle nada, lo sigue presionando para saber su punto de vista. El soldado norcoreano enciende un cigarro y acto seguido la comisionada le dice sobre su partida del punto fronterizo, y le pregunta su sentir ante su retiro. Este sólo atina en contestarle que le dé el encendedor con el que había prendido su cigarro a su compañero del Sur. La funcionaria vuelve a entrevistar al soldado de la mina y le comenta lo sucedido con su par del Norte, incluyendo lo del encendedor y le dice que este le había mencionado que él había matado a su amigo norteño y no el suicida. Esta declaración perturba al soldado de la mina, la comisionada lo abraza y se lo llevan. Pero, el soldado deja el encendedor, y cuando la oficial se asoma por la ventana para devolvérselo, el soldado de la mina le quita el arma a uno de sus custodios y logra suicidarse. Como señal de la amistad cortada por la guerra, al dispararse, el cineasta Park Chan-Wook muestra un charco de sangre, y en medio de este, el detonador de la mina que le había salvado la vida un tiempo atrás. La comisionada baja aturdida al lugar del suicidio y muestra cierta culpa por lo acontecido. En siete días de interrogatorios se había resuelto el problema por parte de la oficial suiza: no hubo realmente culpables por el enfrentamiento. Mientras tanto, seguiría la tensión en el Área de Seguridad Conjunta.

\section{Conclusiones}

De alguna manera, la comisionada fue el vehículo del director Park para atar cabos de lo ocurrido. Su conexión con el conflicto (vía su padre), la puso como una jueza imparcial deseosa de conocer las causas, al menos, las de esta nueva coyuntura. Al final, el resultado visto en la cinta dejó las cosas igual de tensas entre los dos lados. En la película se presentaron varios muertos y se mostró el lado sensible y emotivo de los protagonistas, pero como anunciando la realidad, la conclusión cinematográfica fue contundente: una tensión permanente entre las dos Coreas.

Aunque, la representación cinematográfica ofrece una esperanza pacifista al espectador, y lo hace mediante las últimas imágenes del filme, que evocan la amistad de los soldados. En la última toma, aparecen todos los soldados involucrados en señal de conciliación. El soldado salvador del Norte aparece dando la gorra a la turista; su compañero norteño sale al fondo sonriendo; el soldado del Sur compañero de la base monta una guardia en la línea; y el soldado sureño salvado en la mina emerge dando paso a los turistas. Enseguida viene un acto simbólico que enmarca el mensaje del cineasta Park con respecto a la película: la amistad puede derrumbar las fronteras ideológicas de los hombres. Y como muestra insistente de los valores fraternos, salen imágenes de los protagonistas riéndose en todo momento, como en señal de voluntad 
al diálogo. Este es el cierre magistral de la cinta Área de Seguridad Conjunta, pues el director, aprovechando la influencia del Cine, interpreta este tema complejo y complicado y lo presenta a los espectadores para que juzguen y reflexionen el problema.

\section{Referencias}

Burke, Peter. (2001). Visto y no visto. El uso de la imagen como documento histórico. Barcelona: Crítica.

Escalona Agüero, Alejandro. (2009). “Corea del Norte”, en José Luis Manríquez (Coordinador). Historia mínima de Corea. México: El Colegio de México.

Ferro, M. (2005). “A quién le pertenecen las imágenes”. Istor, (20), pp.49-60.

Hyong, Sik Shin. (2008). A brief History of Korea. Seoul: Ewha Womans University Press.

Kracauer, Siegfried. (2005). Teoría del cine. La redención de la realidad fisica. Barcelona: Paidós.

Pike, Francis. (2010). Empires at War. A short history of modern Asia since World War II. New York: I.B. Tauris.

Rosenstone, Robert A. (2014). "La película histórica como campo, como modo de pensamiento (historiar) y un montón de malas jugadas que les hacemos a los muertos”, en Ángel Luis Hueso Montón y Gloria Camarero Gómez (Coords.). Hacer historia con imágenes. Madrid: Editorial Síntesis.

Sorlin, Pierre. (1985) Sociología del cine. La apertura para la historia del mañana. México: Fondo de Cultura Económica.

http://decine21.com/Biografias/Park-Chan-wook-54816. 30 de agosto de 2016.

http://www.imdb.com/name/nm0661791/?ref_=fn_al_nm_1. 30 de agosto de 2016.

http://decine21.com/Biografias/Park-Chan-wook-54816. 3 de septiembre de 2016. 